\title{
Current Utilization of Labor
}

Unemployment has averaged about 5 per cent of the civilian labor force since May. This rate is up from about 3.5 per cent in late 1968 and 1969 , and has been given much attention as an indication of an underutilization of labor and accompanying hardship.

Some unemployment is unavoidable when workers are free to leave jobs in search of better opportunities, when some positions are seasonal, when some people are incapable of working, and when businesses are forced to cut back or close because they are no longer competitive. Estimates vary as to what level of unemployment would develop with total spending rising at the fastest rate consistent in the long run with price stability or a constant rate of inflation. Unemployment has on occasion fallen below such a minimum, but only as a temporary effect of an excessive amount of spend ing which also has caused an acceleration of price increases.

In evaluating the unemployment situation, some comparisons with previous periods may be helpful. The average 5 per cent memployment rate since May is slightly below the 5.2 per cent rate in 1964, generally considered a year of high economic activity and the last year with a relatively moderate price trend. In the 1962-63 period, the unemployment rate ffuctuated between 5.5 and 6 per cent, and in the interval between the 1958 and 1960 business cycle troughs, the rate fell to about $5 \mathrm{per}$ cent. During these two periods when downward pressure was applied to the rise in prices, unemployment rose to 7 per cent and above.

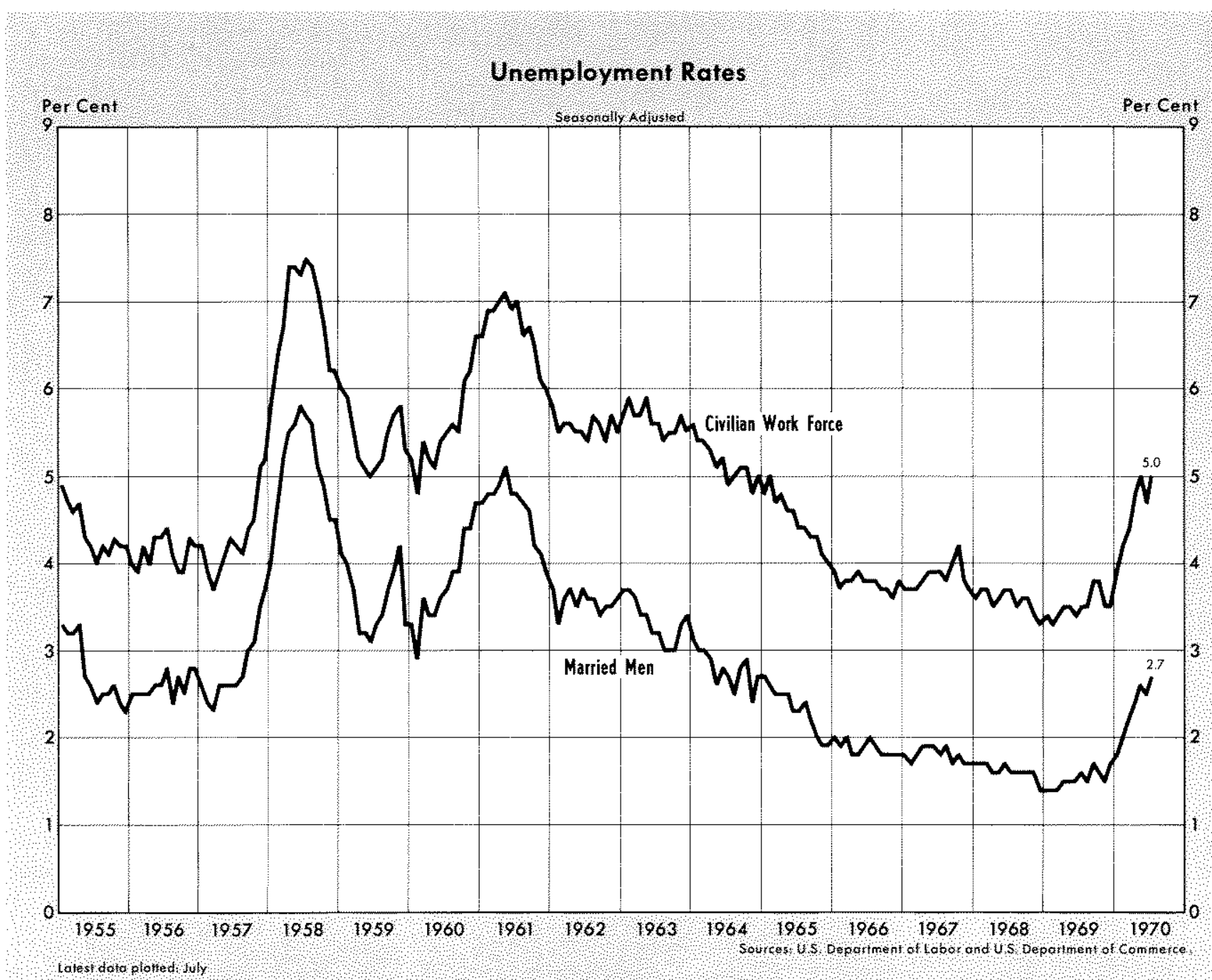


Total Civilian Employment

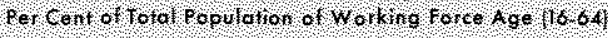

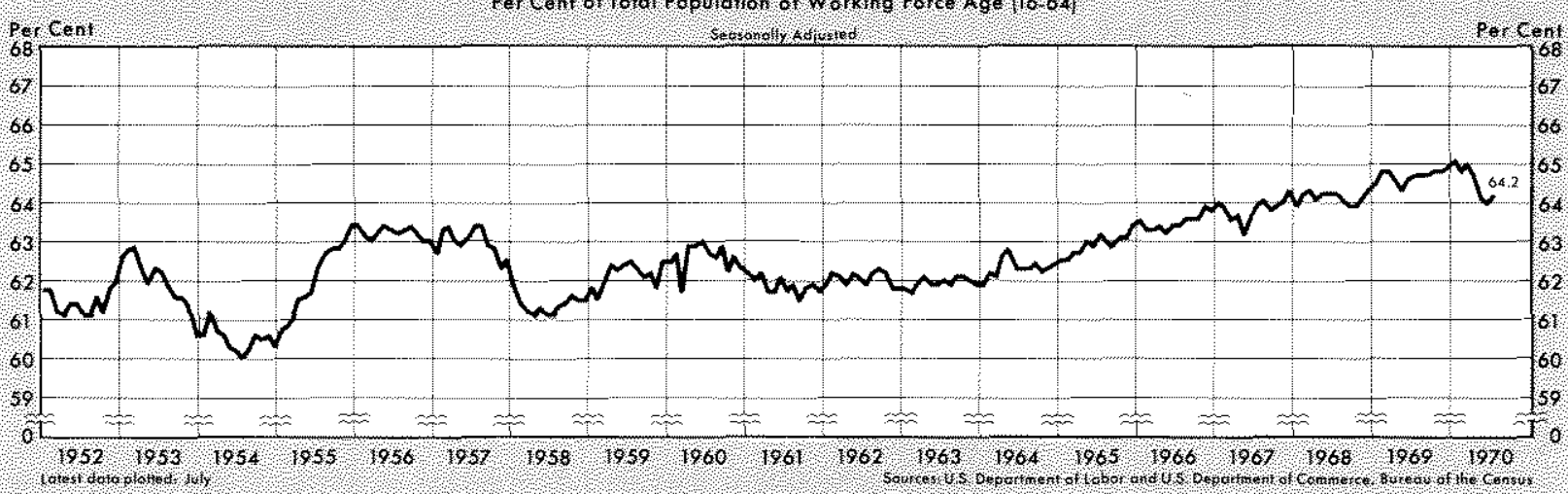

As a measure of hardship or of unemployment conditions among those most seriously seeking work, unemployment among married men may be better than the overall unemployment rate. As can be seen in the chart, the current level of about 2.7 per cent is even more favorable than the overall rate compared with other periods since early 1955.

Another measure of atilization of labor resources relates the total number of people actually working to the civilian population of working force age. The July level of 64.2 per cent on this measure is down from the peak but is still higher than at any time between 1952 and 1967.

Another indication of utilization of labor is the duram tion of unemployment. In July, the average length of unemployment was 9.3 weeks. This is up from about 8 weeks in 1969 , but down substantially from the 12 week or longer periods from 1958 to early 1965. Unemployment insurance and other benefits reduce the social costs of such temporary idleness, and may increase the average length of "hunting" time between jobs as people are better able to reject less desirable alternatives.

With present market restraints and inefficiencies, it is not a sustainable situation to hold the unemployment rate at 1969 levels by stimulating total spending, since price increases are thereby accelerated. A level of unemployment above 5 per cent may develop temporarily while spending is restrained to reduce inflation and inflationary expectations. A fundamental attack on the unemployment problem might focus on the inefficiencies and restrictions in this market, by providing better in formation on job opportunities, increasing mobility of labor, providing more education, training of skills, and removing restrictions on employment.

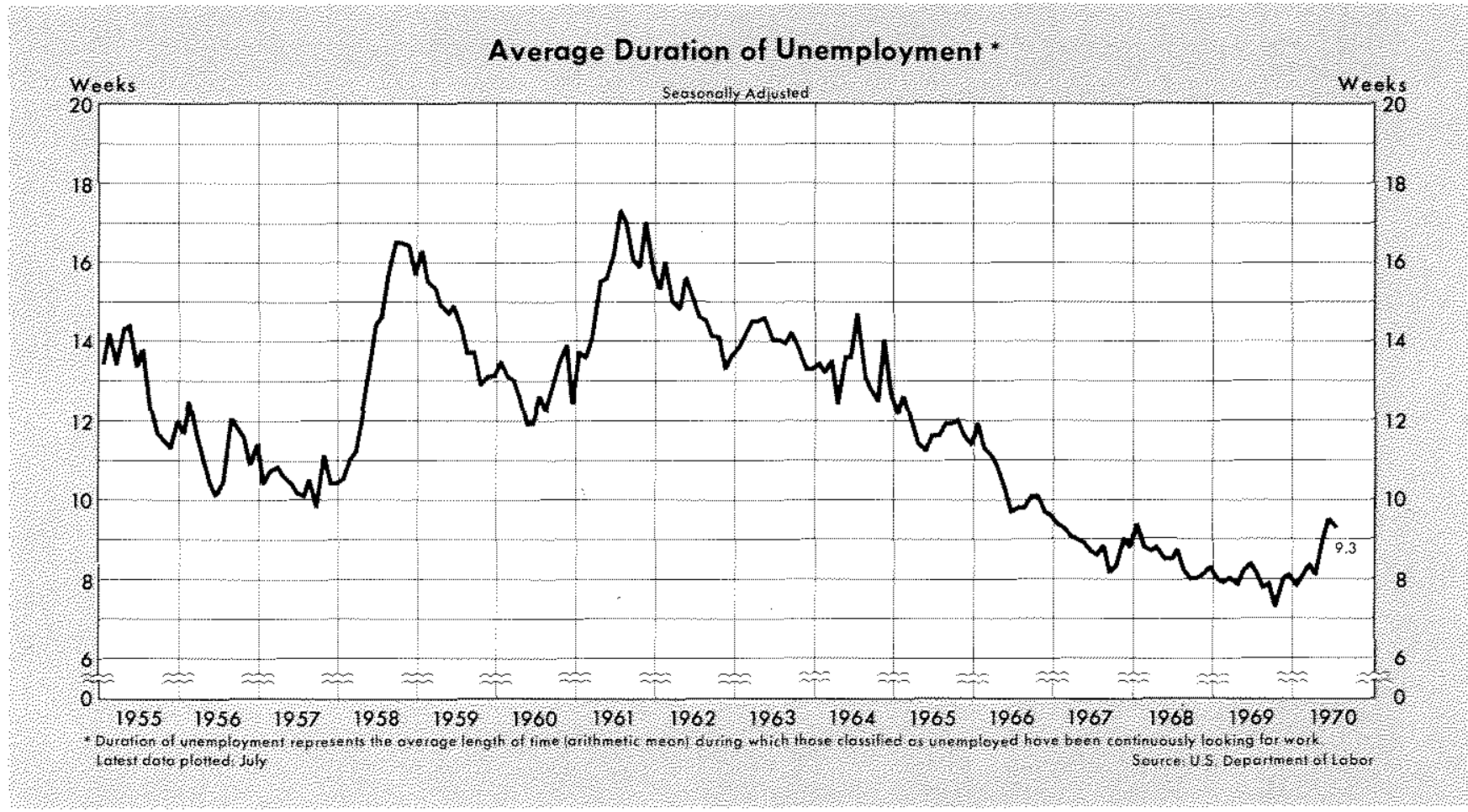

